\title{
Are slab contributions to the wedge oxidized?
}

\author{
E.COTTRELL ${ }^{1 *}$, M. HOLYCROSS ${ }^{1}$, C.H.LANGMUIR ${ }^{2}$
}

${ }^{1} \mathrm{NMNH}$, Smithsonian, Washington, DC, USA

(*correspondence: cottrelle@si.edu)

${ }^{2}$ EPS, Harvard University, Boston, MA, USA

Construction of Fe-depleted, calc-alkaline continental crust occurs at subduction zones, where fluids released from the slab flux the mantle and enable melting [1]. At the same extent of crystal fractionation, basalts chemistry at arc-front and back-arc volcanoes reflects fluid addition and oxidation relative to mid-ocean ridge basalts [2], but is the correlation causal, and if so, what is the mechanism of oxidation? We explore two avenues to make progress.

Slab lithologies may provide clues, but the number of observations that enable calculation of oxygen fugacity $\left(f \mathrm{O}_{2}\right)$ for slab lithologies are limited, and results are scattered - possibly due to high natural variability, but possibly because extant oxybarometers have limited, or even nonexistent, experimental calibrations. We present results from new laboratory experiments that take advantage of vanadium's (V) heterovalency to calibrate V-in-rutilebased oxybarometers [3] that can be rapidly and easily applied to slab lithologies, along with preliminary applications to eclogites. Such developments should move the community forward as we seek to causally link slab processes to arc chemistry.

To compliment this, we examine heterovalent trace element concentrations in arc and back-arc basalts in the context of overall trace element systemmatics. Scrutiny of these elements has the potential to not only ferret out variations in $f \mathrm{O}_{2}$ (e.g. [4]), but arc-specific contributions from the slab, wedge, or arclogites, that will bring us closer to describing causal links between subduction zone processes and the elevated $f \mathrm{O}_{2} \mathrm{~S}$ of arc lavas that drive construction of the continents.

[1] Gill (1981) [2] Brounce et al. (2014) JPET [3] Holycross and Cottrell (2019) Fall AGU [4] Lee et al. (2005) JPET 